\title{
Relation between self-recalled childhood physical activity and adult physical activity: The women's health initiative
}

\author{
Deborah Goodman ${ }^{1}$, Hannah L. Park ${ }^{1}$, Marcia Stefanick ${ }^{2}$, Erin LeBlanc ${ }^{3}$, Jennifer Bea ${ }^{4}$, Lihong Qi ${ }^{5}$, \\ Kristopher Kapphahn' ${ }^{2}$ Michael Lamonte ${ }^{6}$, Tood Manini ${ }^{7}$, Manisha Desai ${ }^{2}$, Hoda Anton-Culver ${ }^{1}$ \\ ${ }^{1}$ Department of Epidemiology, University of California, Irvine, USA \\ ${ }^{2} \mathrm{~S}$ Stanford Prevention Research Center, Stanford University, Palo Alto, USA \\ ${ }^{3}$ Center for Health Research, Kaiser Permanente, Portland, USA \\ ${ }^{4}$ Cancer Center, University of Arizona, Tuscon, Arizona, USA \\ ${ }^{5}$ Department of Public Health, University of California Davis, Sacramento, USA \\ ${ }^{6}$ Department of Social and Preventive Medicine, University at Buffalo, Buffalo, USA \\ ${ }^{7}$ Institute on Aging, University of Florida, Gainesville, USA \\ Email: goodmand@uci.edu
}

Received 27 September 2013; revised 27 October 2013; accepted 4 November 2013

Copyright (C) 2013 Deborah Goodman et al. This is an open access article distributed under the Creative Commons Attribution License, which permits unrestricted use, distribution, and reproduction in any medium, provided the original work is properly cited.

\begin{abstract}
Background: Evidence suggests that childhood physical activity may play a role in the etiology and prevention of adult chronic diseases. Because researchers must often depend on self-recalled physical activity data many years after the exposure, it is important to understand factors which may influence adult recall of childhood physical activity. This study evaluated the influence of adult characteristics on reported childhood physical activity and the association between adult physical activity and self-recalled childhood physical activity. Methods: 48,066 post-menopausal women from the Women's Health Initiative Observational Study reported their physical activity level during ages 5 - 9, 10 - 14, and 15 - 19. Results: In this cohort, over $65 \%$ of the population reported the same category of physical activity over the three childhood age groups. While higher levels of childhood physical activity were significantly associated with higher adult physical activity, this association varied by race/ethnicity, education, smoking, body mass index, history of diabetes or cardiovascular disease, social support and physical functional status. Women who were consistently highly active reported adult physical activity levels that were $2.82 \mathrm{MET}$-hr/week (95\% C.I. $=2.43$, 3.20) higher compared to women who were always physically inactive during childhood. Conclusions: It is important for researchers to understand the influence of adult characteristics on reported childhood physical activity.
\end{abstract}

Keywords: Adult; Childhood; Physical Activity; Self-Reported

\section{INTRODUCTION}

Physical activity during the adult years has been shown to have protective effects against a number of chronic diseases, including Type 2 diabetes, atherosclerosis, ischemic heart disease, heart failure, depression, and several cancers including colon and breast [1,2]. Possible mechanisms in which physical activity may reduce the risk of these diseases include a reduction in hypertension, dyslipidemia, and inflammatory and hemostatic biomarkers [3], an increase in plasticity of the hippocampus, an area of the brain involved in depression [4], and a decrease in adiposity, sex hormones, insulin resistance, and adipokines [5]. The latent period between exposure and the clinical onset of these chronic diseases may be several decades, and recent evidence suggests that exposures during childhood and adolescence may play a role in the etiology and prevention of chronic diseases in adult life [6].

The timing, quality, and quantity of childhood physical activity necessary to prevent disease are not well elucidated. In addition, the influence of childhood physical activity on adult physical activity is not well described. A previous study in this cohort tracked vigorous leisure-time activity through women's adult life and found that, consistent with other studies $[7,8]$, the prevalence of current participation in vigorous activity declined with age and that activity at 50 years of age was more predictive of current activity than participation 
at age 18 or 35 [9]. Because researchers must often depend on self-recalled physical activity data many years after the exposure, it is important to understand factors which may influence adult recall of childhood physical activity.

The WHI observational study (WHI-OS) is uniquely positioned to study this question because of its large number of postmenopausal women, data on self-reported levels of baseline adult and childhood physical activity (including data for ages 5-9, 10 - 14, 15 - 19) as well as a large number of descriptive and potentially confounding data. We examined the relation between baseline adult physical activity and self-reports of childhood physical activity, and described attributes of women by longitudinal patterns of physical activity throughout childhood and adulthood in the WHI-OS cohort. An understanding of how childhood physical activity relates to adult physical activity is important for understanding the contribution of childhood activity to adult health outcomes.

\section{METHODS}

The Women's Health Initiative Observational Study is a large, multi-center prospective cohort study of postmenopausal women. The WHI-OS recruited 93,676 postmenopausal women ages 50 - 79 from 40 clinical centers between 1993 and 1998 to be followed for the development of the most common causes of death. Women were excluded from the WHI-OS if they had an existing medical condition with a survival time of less than 3 years, if they had characteristics which may effect study participation, or if they were active participants in another randomized controlled clinical trial. Details of the design of the study, as well as the baseline measures and their reliability, have been published previously [10-12].

\subsection{Physical Activity Assessment}

Childhood physical activity data was collected at the Year 3 Visit. WHI-OS participants were asked to recall the number of days per week they participated in strenuous physical activity at ages 5-9,10-14, and $15-19$ for at least 20 minutes per day. Assessment of the reliability of long-term recall of physical activity from the Buffalo Health Study found correlations ranging from $0.20-0.50$ [13] and was shown to usually underestimate past physical activity [14]. Information on usual physical activity during adulthood was collected at baseline. Women were asked how often (none, 1, 2, 3, 5, or 5 or more days per week) they walked outside the home for $10 \mathrm{mi}-$ nutes or more without stopping and how often they exercised in three intensity-specific levels of activity: strenuous or very hard exercise, moderate exercise, and mild exercise, for which examples of like activities were given to cue participant recall. Women were also asked the duration spent at each of these activity levels (less than 20 minutes, 20 - 39 minutes, 40 - 59 minutes, 1 hour or more). Adult physical activity levels at baseline were summarized as weekly energy expenditure [metabolic equivalent (MET) hours per week; MET-hr/wk] calculated by multiplying the number of hours per week by the MET intensity value of the activity and adding all types of activities [15]. The reliability [16] and validity [17] of the WHI physical activity questionnaire have been demonstrated elsewhere.

\subsection{Covariate Assessment}

At study enrollment, self-administered questionnaires collected information on participant demographics, medical, reproductive, and family histories, lifestyle factors including smoking history and alcohol consumption, and baseline height and weight. Body mass index (BMI), calculated as weight in kilograms divided by the square of height in meters, was used as an estimate of obesity status. Waist-hip-ratio (WHR), calculated as the waist circumference $(\mathrm{cm})$ divided by the hip circumference $(\mathrm{cm})$, was used as an estimate of body fat distribution. A Physical Functioning Index score was determined by adding the response values of a 10-item physical functioning subscale of the SF-36 [18] and has been shown to have high validity and reliability [19]. The Healthy Eating Index 2005, a standardized measure of diet quality based on the recommendations in MyPyramid [20], was constructed by summing 12 dietary components [21], and a Social Support Index score was measured by adding the response values of 9 items from the Medical Outcomes Study [22].

\subsection{Statistical Analysis}

Childhood physical activity recalled at ages 5-9, $10-14$, and 15 - 19 was categorized into three levels; physically inactive (0 - 1 days/week), low physical activity (2 - 3 days/week), and high physical activity ( $\geq 4$ days/ week). In addition, a youth activity dose of physical activity was calculated by multiplying recalled number of days per week of strenuous activity for each age grouping by the number of years in each age grouping (5 years for each) and then summing across all three age groupings. Subjects could indicate participation in strenuous activity for $0,1,2,3,4,5$ - 7 days in each age grouping; 5 - 7 days were counted as 5 days in the calculation of the youth activity dose variable. Longitudinal childhood physical activity profiles were defined as 1) always inactive (physical inactivity reported for all three childhood age intervals); 2) always lowly active (physical activity reported as low for all three childhood age intervals); 3) always 
highly active (physical activity reported as high for all three childhood age intervals); 4) increased (reported physical activity changed from inactive to low or low to high as subject progressed from younger to older age groups); 5) decreased (reported physical activity changed from high to low or inactive as subject progressed from younger to older age groups; or 6) fluctuated as there was not a linear or consistent pattern to reported physical activity across the three age groups.

Baseline characteristics of the study population, including the distribution of potential confounders, were evaluated using Chi-square tests for categorical data and Kruskal-Wallis tests for continuous variables. Linear regression was used to estimate unadjusted and adjusted associations between dose category of youth physical activity and baseline adult physical activity along with 95\% confidence intervals. All confounders were chosen a priori, based on potential associations previously described in the literature and included age, education, race, waist-hip ratio, social support index, baseline BMI, smoking history, baseline alcohol consumption, Healthy Eating index, physical functioning index, and history of cancer, CVD, diabetes, or hypertension. Linear regression was also used to examine the association between adult physical activity level and childhood activity profile. Analyses were performed using Statistical Analysis System software (SAS Institute, Inc., Cary, North Carolina) and R (R Foundation for Statistical Computing, Vienna, Austria). All statistical tests were two-tailed and conducted at the 0.05 level of significance.

\section{RESULTS}

\subsection{Overall Characteristics of the Cohort}

A total of 93,676 women enrolled in the observational study arm of the WHI [23]. Those missing data on key variables were excluded from the analysis $(32,570$ women were excluded due to missing youth or baseline physical activity data, and 13,040 women were excluded due to missing key confounders), yielding an analytic cohort of 48,066.

The average age at baseline was 63 years ( 7.3 years) with a median of 63 years $(\mathrm{IQR}=12$ years $)$ and a range of 49 - 79 years. The racial/ethnic distribution of the population was $87.2 \%$ non-Hispanic white, $5.9 \%$ non-Hispanic black, 3.0\% Hispanic/ Latino, 2.5\% Asian or Pacific Islander, $0.3 \%$ American Indian, and 1\% classified as "Other". In this cohort, the greatest physical inactivity was reported in the oldest age group, with $23.2 \%, 17.0 \%$, and $17.8 \%$ of women reported childhood physical inactivity during the age intervals 5 - 9 years, 10 - 14 years, and 15 - 19 years, respectively. Low childhood physical activity levels were reported in $17.4 \%$ (ages 5 - 9 years), $20.2 \%$ (ages 10 - 14 years), and 25.8\% (15 - 19 years) of women. The highest childhood physical activity levels were reported in the $10-14$ year old age group; $59.5 \%$ for ages 5 - 9 years, $62.8 \%$ for ages 10 - 14 years, and $56.4 \%$ for 15 - 19 years. The distribution of youth activity dose (YAD) is shown in Figure 1. Almost two-thirds of the cohort reported the highest youth activity dose; $65.2 \%$ reported a youth activity dose of 50 - 75 dayyr/week, $17.6 \%$ reported a youth activity dose of 25 - 49 day-yr/week and $17.2 \%$ reported a youth activity dose of 10 - 24 day-yr/week.

\subsection{Baseline Characteristics of the Cohort by Childhood Physical Activity}

The distribution of participant baseline characteristics by level of childhood physical activity at ages 5 - 9 years, 10 - 14 years, and 15 - 19 years is shown in Table 1. Baseline study population characteristics were similar across all childhood age groupings. Hispanic/Latino and Asian/Pacific Islanders, those with less than a high school education, history of never smoking, and higher

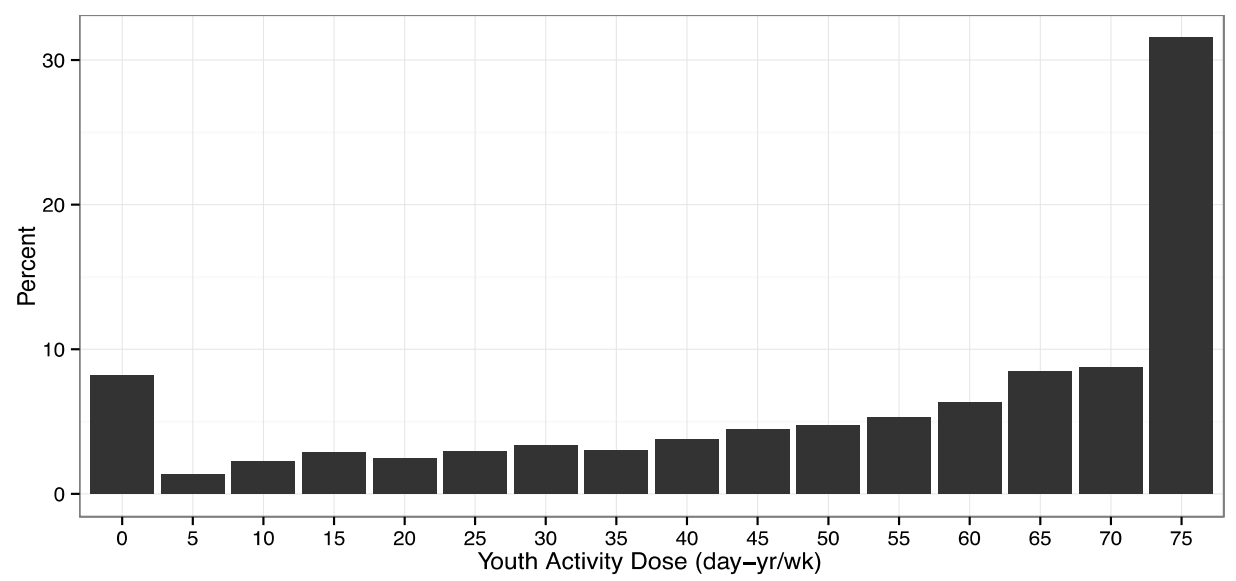

Figure 1. Distribution of youth activity dose (Day-Yr/Wk) across the WHI-OS cohort. 
Table 1. Distribution of baseline characteristics by childhood physical activity profiles.

\begin{tabular}{|c|c|c|c|c|c|c|c|c|c|c|c|c|}
\hline & \multicolumn{4}{|c|}{ Physical Activity Level Ages 5 - 9} & \multicolumn{4}{|c|}{ Physical Activity Level Ages 10 - 14} & \multicolumn{4}{|c|}{ Physical Activity Level Ages 15 - 19} \\
\hline & Inactive & Low & High & p-value ${ }^{*}$ & Inactive & Low & High & p-value ${ }^{*}$ & Inactive & Low & High & p-value ${ }^{*}$ \\
\hline Sample Size & 11,132 & 8353 & 28,581 & & 8149 & 9721 & 30,196 & & 8559 & 12,415 & 27,092 & \\
\hline Age & $\%$ & $\%$ & $\%$ & 0.178 & $\%$ & $\%$ & $\%$ & $<0.001$ & $\%$ & $\%$ & $\%$ & $<0.001$ \\
\hline 50 to 54 & 14.3 & 15.3 & 14.5 & & 15.4 & 16.4 & 13.8 & & 16.9 & 16.1 & 13.2 & \\
\hline 55 to 59 & 19.2 & 20 & 19.9 & & 19.6 & 19.9 & 19.7 & & 20.6 & 20.5 & 19.1 & \\
\hline 60 to 69 & 44.4 & 43.4 & 44 & & 44.1 & 43.1 & 44.3 & & 42.9 & 43.7 & 44.5 & \\
\hline 70 to 79 & 22 & 21.3 & 21.5 & & 20.9 & 20.5 & 22.2 & & 19.6 & 19.6 & 23.2 & \\
\hline Race & $\%$ & $\%$ & $\%$ & $<0.001$ & $\%$ & $\%$ & $\%$ & $<0.001$ & $\%$ & $\%$ & $\%$ & $<0.001$ \\
\hline $\begin{array}{l}\text { White (not of } \\
\text { Hispanic origin) }\end{array}$ & 86 & 87.9 & 87.5 & & 86.1 & 88.8 & 87 & & 86.4 & 89 & 86.6 & \\
\hline $\begin{array}{c}\text { Black or } \\
\text { African-American }\end{array}$ & 5.2 & 5.2 & 6.4 & & 4.8 & 4.5 & 6.7 & & 4.8 & 4.7 & 6.8 & \\
\hline Hispanic/Latino & 3.4 & 2.9 & 2.8 & & 3.4 & 2.7 & 3 & & 3.2 & 2.6 & 3.1 & \\
\hline Asian or Pacific Islander & 3.9 & 2.6 & 1.9 & & 4.3 & 2.6 & 2 & & 4.2 & 2.6 & 1.9 & \\
\hline $\begin{array}{l}\text { American Indian or } \\
\text { Alaskan Native }\end{array}$ & 0.3 & 0.3 & 0.4 & & 0.2 & 0.2 & 0.4 & & 0.3 & 0.2 & 0.4 & \\
\hline Other & 1.2 & 1 & 1 & & 1.1 & 1 & 1 & & 1.1 & 0.9 & 1.1 & \\
\hline Education & $\%$ & $\%$ & $\%$ & $<0.001$ & $\%$ & $\%$ & $\%$ & $<0.001$ & $\%$ & $\%$ & $\%$ & $<0.001$ \\
\hline $\begin{array}{l}\text { Less than High } \\
\text { School Diploma }\end{array}$ & 4.4 & 2.9 & 3 & & 4.2 & 2.7 & 3.3 & & 4.2 & 2.2 & 3.5 & \\
\hline High School Diploma & 48.4 & 48.2 & 50.9 & & 46.7 & 46 & 51.9 & & 46.3 & 45.4 & 53 & \\
\hline College Degree & 47.2 & 48.9 & 46.1 & & 49.1 & 51.4 & 44.8 & & 49.5 & 52.4 & 43.5 & \\
\hline BMI at Baseline & $\%$ & $\%$ & $\%$ & $<0.001$ & $\%$ & $\%$ & $\%$ & $<0.001$ & $\%$ & $\%$ & $\%$ & $<0.001$ \\
\hline $0-25.0$ & 47.7 & 44.6 & 39.6 & & 48.2 & 46.1 & 39.6 & & 48.8 & 46 & 38.6 & \\
\hline $25.0-30.0$ & 33 & 33.8 & 34.1 & & 33.1 & 33.2 & 34.2 & & 32.7 & 33.4 & 34.3 & \\
\hline $30.0-70.0$ & 19.3 & 21.6 & 26.3 & & 18.7 & 20.8 & 26.2 & & 18.5 & 20.5 & 27.1 & \\
\hline Alcohol & $\%$ & $\%$ & $\%$ & $<0.001$ & $\%$ & $\%$ & $\%$ & $<0.001$ & $\%$ & $\%$ & $\%$ & $<0.001$ \\
\hline Non drinker & 10.4 & 9.8 & 9.8 & & 10 & 9 & 10.2 & & 9.9 & 8.5 & 10.6 & \\
\hline Past drinker & 16 & 16.1 & 18.5 & & 15.4 & 15.3 & 18.7 & & 15.5 & 14.9 & 19.2 & \\
\hline$<1$ drink per month & 11.1 & 10.4 & 11.7 & & 11.2 & 10.8 & 11.6 & & 11.1 & 11 & 11.6 & \\
\hline$<1$ drink per week & 21.1 & 21.1 & 19.9 & & 21.4 & 21.2 & 19.8 & & 21.2 & 20.7 & 19.9 & \\
\hline 1 to $<7$ drinks per week & 27.6 & 29.4 & 26.7 & & 27.7 & 29.9 & 26.4 & & 27.5 & 30.3 & 25.9 & \\
\hline $7+$ drinks per week & 13.9 & 13.2 & 13.5 & & 14.3 & 13.8 & 13.2 & & 14.7 & 14.6 & 12.7 & \\
\hline Smoking History & $\%$ & $\%$ & $\%$ & $<0.001$ & $\%$ & $\%$ & $\%$ & $<0.001$ & $\%$ & $\%$ & $\%$ & $<0.001$ \\
\hline Never Smoked & 54.5 & 51.9 & 49.4 & & 53.8 & 51 & 50.3 & & 52.8 & 49.9 & 51 & \\
\hline Past Smoker & 41.1 & 42.8 & 44.3 & & 41.6 & 44.3 & 43.4 & & 42.4 & 45.5 & 42.6 & \\
\hline Current Smoker & 4.4 & 5.3 & 6.3 & & 4.6 & 4.8 & 6.3 & & 4.8 & 4.6 & 6.5 & \\
\hline History of diabetes & $\%$ & $\%$ & $\%$ & $<0.001$ & $\%$ & $\%$ & $\%$ & $<0.001$ & $\%$ & $\%$ & $\%$ & $<0.001$ \\
\hline Yes & 4.2 & 4.1 & 5.2 & & 4 & 4.2 & 5.1 & & 4 & 4 & 5.4 & \\
\hline History of CVD & $\%$ & $\%$ & $\%$ & $<0.001$ & $\%$ & $\%$ & $\%$ & $<0.001$ & $\%$ & $\%$ & $\%$ & $<0.001$ \\
\hline Yes & 17 & 16.7 & 19.7 & & 16.7 & 16.6 & 19.7 & & 16.3 & 17.1 & 19.9 & \\
\hline History of cancer & $\%$ & $\%$ & $\%$ & 0.11 & $\%$ & $\%$ & $\%$ & 0.079 & $\%$ & $\%$ & $\%$ & 0.072 \\
\hline Yes & 12.3 & 12.8 & 13.1 & & 12.5 & 12.4 & 13.1 & & 12.3 & 12.7 & 13.2 & \\
\hline
\end{tabular}

"p-value: comparison of the baseline characteristic over the three youth activity levels (inactive, low, high). 
baseline physical functional status were more likely to report physical inactivity at ages $5-9,10-14$, and 15 19 years than they were to report low or high activity. Women who were older, overweight or obese at baseline, had a greater WHR, reported a history of diabetes or cardiovascular disease (CVD), had higher baseline levels of social support, former drinkers, and smokers at baseline were significantly more likely to report high levels of physical activity during all childhood time intervals than they were to report low or no activity. No association was seen between childhood physical activity level and history of cancer at baseline. While baseline adult Healthy Eating Index 2005 was not significantly associated with childhood physical activity at ages $5-9$ or $10-14$ years, a significant association did exist for the $15-19$ years age group.

\subsection{Consistency of Physical Activity during Childhood}

Over $65 \%$ of the population reported the same category of physical activity over the three childhood age groups. "High" levels of childhood physical activity over all age periods was reported by $45.4 \%$ of women while only $7 \%$ reported "low" childhood activity over all age groups and $12.8 \%$ reported inactivity over all age groups (Table 2). $16.5 \%$ reported increasing in physical activity over the three age groups, and $15.5 \%$ reported decreasing in activity. Only $2.8 \%$ reported fluctuating between different physical activity categories over the three age groups.

\subsection{Association between Childhood and Adult Physical Activity}

Across all childhood age groups, higher levels of childhood physical activity were significantly associated with higher baseline adult physical activity. As shown in Table 3, women with the highest YAD had significantly higher baseline adult physical activity in both unadjusted and adjusted models. For example, those that reported the highest YAD had an increase of 2.2 MET-hr/week $(95 \%$ C.I. $=1.88,2.55)$ of adult physical activity level

Table 2. Distribution of longitudinal childhood physical activity profiles in the WHI-OS cohort.

\begin{tabular}{cc}
\hline Longitudinal Pattern & N (\% of cohort) \\
\hline Always Inactive & $6140(12.8)$ \\
Always Lowly Active & $3354(7.0)$ \\
Always Highly Active & $21,827(45.4)$ \\
Increased & $7933(16.5)$ \\
Decreased & $7469(15.5)$ \\
Fluctuated & $1343(2.8)$ \\
\hline
\end{tabular}

relative to women in the lowest dose category. Likewise, evaluation of longitudinal physical activity patterns across childhood (Table 4) found that compared to women who were always physically inactive during childhood, those who were consistently highly active reported adult physical activity levels that were almost 3 units higher (i.e., a difference in $2.82 \mathrm{MET}-\mathrm{hr} /$ week; 95\% C.I. $=2.43,3.20$ ) after adjusting for confounders, and those who increased childhood activity, had an increase of almost 2 units higher (1.83 MET-hr/week; 95\% C.I. = 1.40, 2.28).

\section{DISCUSSION}

This large observational study found a significant positive association between physical activity at baseline and recalled level of physical activity in childhood. This is in agreement with several previous reliability studies which have shown low to modest correlations between childhood and adult physical activity levels [7,8,24-28]. In addition, evaluation of childhood physical activity patterns showed that consistency of physical activity level during childhood was directly associated with level of adult physical activity. Women who reported consistly high levels of childhood activity also had significantly elevated baseline physical activity. Aligned with our results, another previous trial found that sustained childhood physical activity increased the likelihood of higher levels of adult physical activity [7].

Results of this study also showed that childhood physical activity profiles showed significant increases in baseline physical activity relative to the always inactive group, suggesting that it may not be necessary to sustain physical activity throughout childhood to see positive benefits. This study also found that childhood physical activity level varied significantly by several participant baseline characteristics including race/ethnicity, education, smoking history, adult BMI, adult WHR, history of diabetes or cardiovascular disease, adult social support and physical functional status. Others also have shown similar differences in reported physical activity level by race/ethnicity and education [29]. We found that obese adults reported higher levels of childhood physical activity, and it has been demonstrated that overweight girls and adults frequently overreport physical activity [30-32]. In a recent study comparing physical activity biomarkers and self-reported physical activity in the WHI-OS, BMI was associated with under-reporting of physical activity on two questionnaires [33]. While smoking in childhood has been shown to be inversely associated to persistant physical activity from adolescence through early adulthood [34], to our knowledge we are the first to show that past drinkers and smokers reported higher levels of childhood physical activity. In addition, while social support has been shown to be positively associated with 
Table 3. Unadjusted and adjusted baseline adult physical activity (MET-Hr/Week) for each youth activity dose category.

\begin{tabular}{|c|c|c|c|c|c|c|}
\hline $\begin{array}{l}\text { Youth Activity Dose } \\
\text { Category }\end{array}$ & $\begin{array}{c}\text { Unadjusted Estimate }(95 \% \mathrm{CI}) \\
\text { of Adult Physical Activity } \\
\text { (MET-hr/week) }\end{array}$ & P-Value & $\mathrm{R}^{2}$ & $\begin{array}{c}\text { Adjusted Estimate }(95 \% \text { CI) } \\
\text { of Adult Physical Activity } \\
\text { (MET-hr/week }\end{array}$ & P-Value & $\mathrm{R}^{2}$ \\
\hline 0 - 24 day-yr/wk & Reference & & & Reference & $<0.001$ & 0.12 \\
\hline 25 - 49 day-yr/wk & $0.77(0.35,1.20)$ & $<0.001$ & 0.001 & $0.80(0.38,1.21)$ & & \\
\hline 50 - 75 day-yr/wk & $1.39(1.05,1.73)$ & & & $2.22(1.88,2.55)$ & & \\
\hline
\end{tabular}

*Adjusted for baseline age, education, race, WHR, social support index, baseline BMI, smoking, Healthy Eating Index 2005, physical functional status index, history of cancer, CVD, diabetes, or hypertension. ${ }^{* *}$ Youth Activity Dose is a composite of self-reported physical activity for the 3 childhood age groups.

Table 4. Unadjusted and adjusted baseline adult physical activity (MET-Hr/Week) for each longitudinal youth activity category.

\begin{tabular}{|c|c|c|c|c|c|c|}
\hline Longitudinal Pattern & $\begin{array}{c}\text { Unadjusted Estimate (95\% CI) } \\
\text { of Adult Physical } \\
\text { Activity (MET-hr/week) }\end{array}$ & P-Value & $\mathrm{R}^{2}$ & $\begin{array}{c}\text { Adjusted Estimate }(95 \% \text { CI) } \\
\text { of Adult Physical Activity } \\
\text { (MET-hr/week) }\end{array}$ & P-Value & $\mathrm{R}^{2}$ \\
\hline Always Inactive & Reference & \multirow{6}{*}{$<0.001$} & \multirow{6}{*}{0.002} & Reference & \multirow[t]{6}{*}{$<0.001$} & \multirow[t]{6}{*}{0.12} \\
\hline Always Lowly Active & $1.17(0.56,1.79)$ & & & $0.78(0.21,1.36)$ & & \\
\hline Always Highly Active & $1.84(1.43,2.25)$ & & & $2.82(2.43,3.20)$ & & \\
\hline Increased & $1.37(0.88,1.85)$ & & & $1.83(1.40,2.28)$ & & \\
\hline Decreased & $1.15(0.66,1.65)$ & & & $0.91(0.45,1.37)$ & & \\
\hline Fluctuated & $0.82(-0.03,1.69)$ & & & $1.18(0.38,1.99)$ & & \\
\hline
\end{tabular}

physical activity in adults and social isolation significantly associated with physical inactivity [35], to our knowledge, this is the first study to demonstrate an association between adult social support and physical inactivity during childhood. It is important to consider these characteristics as potential confounders in any study evaluating the effect of childhood physical activity.

Strengths of this study include the large, ethnically diverse population-based cohort, and the availability of childhood physical activity beginning at age 5 . This study did not evaluate the validity of childhood physical activity recall. The distribution of reported childhood physical activity, however, was consistent with physical activity levels reported elsewhere [36] and our data supported the previously published decline in physical activity seen during ages $12-21[37,38]$. Although the physical activity recall interval was considerable for this population, Blair et al. found that reliability of longterm physical activity recall was independent of interval length, up to 10 years [39].

In addition, adults who participated in organized childhood sports may have enhanced recall compared to those whose activities were not organized. Although this study did not ask about type of activity, these data showed statistical significance only in the highest levels of activity or the "always active" and "increasing active" categories, and it is possible that participation in organized sports may explain the difference in longitudinal activity patterns. The information on lifestyle factors, including smoking, alcohol use, and social support, was based on self-reported data and thus was subject to recall bias. However, this is a known limitation of retrospective cohort studies and reinforces the importance of including these factors as confounders. Lastly, this study is limited to postmenopausal women and the caution needs to be used when generalizing results to other populations.

Lifelong physical activity patterns, including those during childhood, may play an important role in the etiology of chronic disease and promotion of childhood activity should be encouraged. In addition, it is essential for researchers to understand and account for the influence of adult characteristics on reported childhood physical activity. Further studies are needed to better understand the differential effects on recalled childhood physical activity.

\section{ACKNOWLEDGEMENTS}

We would like to acknowledge the following list of WHI Investigators: Program Office: National Heart, Lung, and Blood Institute, Bethesda, Maryland; Jacques Rossouw, Shari Ludlam, Dale Burwen, Joan McGowan, Leslie Ford, and Nancy Geller Clinical Coordinating Center: (Fred Hutchinson Cancer Research Center, Seattle, WA) Garnet Anderson, Ross Prentice, Andrea LaCroix, and Charles Kooperberg Investigators and Academic Centers: (Brigham and Women's Hospital, Harvard Medical School, Boston, MA) JoAnn E. Manson; (MedStar Health Research Institute/Howard University, Washington, DC) Barbara V. Howard; (Stanford Prevention Research Center, Stanford, CA), Marcia L. Stefanick; (The Ohio State University, Columbus, OH) Rebecca 
Jackson; (University of Arizona, Tucson/Phoenix, AZ) Cynthia A. Thomson; (University at Buffalo, Buffalo, NY) Jean Wactawski-Wende; (University of Florida, Gainesville/Jacksonville, FL) Marian Limacher; (University of Iowa, Iowa City/Davenport, IA) Robert Wallace; (University of Pittsburgh, Pittsburgh, PA) Lewis Kuller; (Wake Forest University School of Medicine, Winston-Salem, NC) Sally Shumaker.

This work was supported by the National Heart, Lung, and Blood Institute, National Institutes of Health, US Department of Health and Human Services through contracts HHSN268201100046C,

HHSN268201100001C, HHSN268201100002C,

HHSN268201100003C, HHSN268201100004C, and

HHSN271201100004C.

\section{REFERENCES}

[1] United States Department of Health and Human Services (1996) Physical activity and health: A report of the surgeon general: Atlanta, GA: Public Health Services, Centers for Disease Control and Prevention, National Center for Chronic Disease Prevention and Health Promotion.

[2] Brown, W.J., Burton, N.W. and Rowan, P.J. (2007) Updating the evidence on physical activity and health in women. American Journal of Preventive Medicine, 33, 404-411. http://dx.doi.org/10.1016/j.amepre.2007.07.029

[3] Mora, S., Cook, N., Buring, J.E., Ridker, P.M. and Lee, I.M. (2007) Physical activity and reduced risk of car-diovascular events: Potential mediating mechanisms. Circulation, 116, 2110-2118.

http://dx.doi.org/10.1161/CIRCULATIONAHA.107.7299 39

[4] Gomez-Pinilla, F., Ying, Z., Roy, R.R., Molteni, R. and Edgerton, V.R. (2002) Voluntary exercise induces a BDNF-mediated mechanism that promotes neuro-plasticity. Journal of Neurophysiology, 88, 2187-2195. http://dx.doi.org/10.1152/jn.00152.2002

[5] Friedenreich, C.M. (2011) Physical activity and breast cancer: Review of the epidemiologic evidence and biologic mechanisms. Recent Results Cancer Research, 188, 125-139. http://dx.doi.org/10.1007/978-3-642-10858-7_11

[6] Gluckman, P.D., Hanson, M.A., Cooper, C. and Thornburg, K.L. (2008) Effect of in utero and early-life conditions on adult health and disease. New England Journal of Medicine, 359, 61-73. http://dx.doi.org/10.1056/NEJMra0708473

[7] Telama, R., Yang, X., Viikari, J., Valimak, I., Wanne, O. and Raitakari, O. (2005) Physical activity from childhood to adulthood: A 21-year tracking study. American Journal of Preventive Medicine, 28, 267-273.

http://dx.doi.org/10.1016/j.amepre.2004.12.003

[8] Cleland, V., Dwyer, T. and Venn, A. (2012) Which domains of childhood physical activity predict physical activity in adulthood? A 20 -year prospective tracking study. British Journal of Sports Medicine, 46, 595-602. http://dx.doi.org/10.1136/bjsports-2011-090508

[9] Evenson, K.R., Wilcox, S., Pettinger, M., Bruner, R., King,
A.C. and McTierman, A. (2002) Vigorous leisure activity through women's adult life. American Journal of Preventive Medicine, 156, 945-953.

[10] The Women's Health Initiative Study Group (1998) Design of the women's health initiative clinical trial and observational study. Control Clinical Trials, 19, 61-109. http://dx.doi.org/10.1016/S0197-2456(97)00078-0

[11] Hays, J., Hunt, J.R., Hubbell, F.A., Anderson, G.L., Limacher, M., Allen, C. and Rossouw, J.E. (2003) The women's health initiative recruitment methods and results. Annals of Epidemiology, 13, S18-S77. http://dx.doi.org/10.1016/S1047-2797(03)00042-5

[12] Langer, R.D., White, E., Lewis, C.E., Kotchen, J.M., Hendrix, S.L. and Trevisan, M. (2003). The women's health initiative observational study: Baseline characteristics of participants and reliability of baseline measures. Annals of Epidemiology, 13, S107-S121. http://dx.doi.org/10.1016/S1047-2797(03)00047-4

[13] Blair, S.N., Dowda, M., Pate, R.R., Kronenfeld, J., Howe, H.G., Parker, G., et al. (1991) Reliability of long-term recall of participation in physical activity by middle-aged men and women. American Journal of Epidemiology, 133, 266-275.

[14] Falkner, K.L., Trevisan, M. and McCann, S.E. (1999) Reliability of recall of physical activity in the distant past. American Journal of Epidemiology, 150, 195-205. http://dx.doi.org/10.1093/oxfordjournals.aje.a009980

[15] Irwin, M.L., McTiernan, A., Manson, J.E., Thomson, C.A., Sternfeld, B., Stefanick, M.L., et al. (2011) Physical activity and survival in postmenopausal women with breast cancer: Results from the women's health initiative. Cancer Prevention Research, 4, 522-529. http://dx.doi.org/10.1158/1940-6207.CAPR-10-0295

[16] Meyer, A.M., Evenson, D.R., Morimoto, L., Siscovick, D. and White, E. (2009) Test-retest reliability of the women's health initiative physical activity questionnaire. Medicine \& Science in Sports \& Exercise, 41, 530-538. http://dx.doi.org/10.1249/MSS.0b013e31818ace55

[17] Johnson-Kozlow, M., Rock, C.L., Gilpin, E.A., Hollenbach, K.A. and Pierce, J.P. (2007) Validation of the WHI brief physical activity questionnaire among women diagnosed with breast cancer. American Journal of Health Behavior, 31, 193-202. http://dx.doi.org/10.5993/AJHB.31.2.8

[18] Hays, R., Sherbourne, C. and Mazel, R. (1993) The rand 36-item survey 1.0. Health Economics, 2, 217-227. http://dx.doi.org/10.1002/hec.4730020305

[19] Wiklund, I., Gorkin, L., Pawitan, Y., Schron, E., Schoenberger, J., Jared, L. and Shumaer, S. (1992) Methods of assessing quality of life in the cardiac arrhythmia suppression trial (CAST). Quality of Life Research, 1, 187201. http://dx.doi.org/10.1007/BF00635618

[20] Britten, P., Marcoe, K., Yamini, S. and Davis, D. (2006) Development of food group composites and nutrient profile for the MyPyramid food guidance system. Journal of Nutrition Education and Behavior, 38, S78-S92. http://dx.doi.org/10.1016/j.jneb.2006.08.007

[21] Chiuve, S.E., Fung, T.T., Rimm, E.B., Hu, F.B., McCullough, M.L., Wang, M., et al. (2012) Alternative dietary 
indices both strongly predict risk of chronic disease. Journal of Nutrition, 142, 1009-1018. http://dx.doi.org/10.3945/jn.111.157222

[22] Sherbourne, S.D. and Stewart, A.L. (1991) The MOS social support survey. Social Science \& Medicine, 32, 705714. http://dx.doi.org/10.1016/0277-9536(91)90150-B

[23] Phipps, A.I., Chlebowski, R.T., Prentice, R., McTiernan, A., Stefanick, M.L., Wactawski-Wende, J., et al. (2011) Body size, physical activity, and risk of triple-negative and estrogen receptor-positive breast cancer. Cancer Epidemiology, Biomarkers \& Prevention, 20, 454-463. http://dx.doi.org/10.1158/1055-9965.EPI-10-0974

[24] Vanreusel, B., Renson, R., Beunen, G., Claessens, A.L., Lefevre, J., Lysens, R.L., et al. (1997) A longitudinal study of youth sport participation and adherence to sport in adulthood. International Review for the Sociology of Sport, 32, 373-387. http://dx.doi.org/10.1177/101269097032004003

[25] Malina, R.M. (2001) Adherence to physical activity from childhood to adulthood: A perspective from tracking studies. Quest, 53, 346-355. http://dx.doi.org/10.1080/00336297.2001.10491751

[26] Tammelin, T., Näyhä, S., Laitinen, J., Rintamäki, H. and Järvelin, M.-J. (2003) Physical activity and social status on adolescence as predictors of physical inactivity in adulthood. Preventive Medicine, 37, 375-381. http://dx.doi.org/10.1016/S0091-7435(03)00162-2

[27] Curtis, J., McTeer, W. and White, P. (1999) Exploring effects of school sport experiences on sport participation in later life. Sociological Sport Journal, 16, 348-365.

[28] Frändin, K., Mellström, D., Dundh, V. and Grimby, G. (1995) A life span perspective on patterns of physical activity and functional performance at the age of 76 . Gerontology, 41, 109-120. http://dx.doi.org/10.1159/000213671

[29] Gordon-Larsen, P., McMurray, R.G. and Popkin, B.M. (2000) Determinants of adolescent physical activity and inactivity patterns. Pediatrics, 105, E83. http://dx.doi.org/10.1542/peds.105.6.e83

[30] McMurray, R.G., Ward, D.S., Elder, J.P., Lytle, L.A., Strikmiller, P.K., Baggett, C.D. and Young, D.R. (2008) Do overweight girls overreport physical activity? American Journal of Health Behavior, 32, 538-546. http://dx.doi.org/10.5993/AJHB.32.5.9

[31] Warner, E.T., Wolin, K.Y., Duncan, D.T., Heil, D.P., Askew, S. and Bennett, G.G. (2012) Differential accuracy of physical activity self-report by weight status. American Journal of Health Behavior, 36, 168-178. http://dx.doi.org/10.5993/AJHB.36.2.3

[32] Timperio Am Salmon, J. and Crawford, D. (2003) Validity and reliability of a physical activity recall instrument among overweight and non-overweight men and women. The Journal of Science and Medicine in Sport, 6, 477 491. http://dx.doi.org/10.1016/S1440-2440(03)80273-6

[33] Neuhouser, M.L., Di, C., Tinker, L.F., Thomson, C., Sternfeld, B., Mossavar-Rahmani, Y., et al. (2013) Physical activity assessment: Biomarkers and self-reported activity-related energy expenditure in the WHI. American Journal of Epidemiology, 15, 576-585.

http://dx.doi.org/10.1093/aje/kws269

[34] Jose, K.A., Blizzard, L., Dwer, T., McKercher, C. and Venn, A.J. (2011) Childhood and adolescent predictors of leisure time physical activity during the transition from adolescence to adulthood: A population based co-hort study. International Journal of Behavioral Nutrition and Physical Activity, 8, 54.

http://dx.doi.org/10.1186/1479-5868-8-54

[35] Willey, J.Z., Paik, M.C., Sacco, R., Elkind, M.S.V. and Boden-Albala, B. (2010) Social determinants of physical inactivity in the Northern Manhattan Study (NO-MAS). Journal of Community Health, 35, 602-608. http://dx.doi.org/10.1007/s10900-010-9249-2

[36] Pratt, M., Macera, C.A. and Blanton, C. (1999) Levels of physical activity and inactivity in children and adults in the United States: current evidence and research issues. Medicine \& Science in Sports \& Exercise, 31, S526S533. http://dx.doi.org/10.1097/00005768-199911001-00007

[37] Caspersen, C.J., Pereira, M.A. and Curran, K.M. (2000) Changes in physical activity patterns in the United States, by sex and cross-sectional age. Medicine \& Science in Sports \& Exercise, 32, 1601-1609. http://dx.doi.org/10.1097/00005768-200009000-00013

[38] Allison, K.R., Adlaf, E.M., Dwyer, J.J.M., Lysy, D.C. and Irving, H.M. (2007) The decline in physical activity among adolescent students. Canadian Journal of Public Health, 98, 97-100.

[39] Blair, S.N., Dowda, M., Pate, R.R., Kronenfeld, J., Howe, H.G., Parker, G., Blair, A. and Fridinger, F. (1991) Reliability of long-term recall of participation in physical activity by middle-aged men and women. American Journal of Epidemiology, 133, 266-275. 